\title{
The range of quantifiers: An empirical investigation of set size
}

\author{
Eva Klingvall \\ Lund University \\ Fredrik Heinat \\ Linnæus University
}

\begin{abstract}
In this paper we present the results from a large-scale estimation study on Swedish Quantified Expressions (QEs). The size of seventeen different QEs, eight positive (monotone increasing) and nine negative (monotone decreasing), was rated by 596 participants. The results show that both positive and negative QEs can pick out large and small quantities and that some QEs are indistinguishable in size. One QE, ett antal ('a number of') has a bimodal distribution, meaning that some speakers interpret it as picking out a large quantity and other speakers as picking out a small quantity. In addition, the results raise interesting questions about the internal structure of QEs and about scalar inferences, among other things.
\end{abstract}

\section{Introduction}

It is a well-known property of quantifying expressions (QEs) that they operate on sets of entities (Barwise and Cooper 1981; Westerståhl 1985; Keenan \& Stavi 1986). That is, they specify the proportion or quantity of entities of a given set for which some property holds. In (1), for example, 'some members' and 'two members' from the set of students are in the set of people who listened carefully:

(1) a. Some of the students listened carefully.

b. Two of the students listened carefully.

Ken Ramshøj Christensen, Henrik Jørgensen \& Johanna L. Wood (eds.). 2019.

The Sign of the V-Papers in Honour of Sten Vikner.

Dept. of English, School of Communication \& Culture, Aarhus University, pp. 385-404, doi:10.7146/aul.348.105. (C) The author(s). 
The QE some differs from two in being vague as to how many members are in the intersection of the relevant sets. Interestingly though, although QEs like some are less exact than QEs like two, they are often more informative, since they convey other types of relevant information, as discussed in Moxey and Sanford (1993a) (see also Westerståhl 1985; Keenan \& Stavi 1986). In their example, for someone wondering whether to book at train ticket or not, it is more useful to be told that there are few tickets lefts, than that there are 45 tickets left. Unless the person knows how many tickets are usually left at this point (i.e. whether 45 is in fact a lot or not many), the information that there are 45 seats left won't be helpful (Moxey \& Sanford 1993a: 4).

Although QEs like some differ in what approximate number they indicate to depending on the context where they are used and the expectations that come with it (see e.g. Moxey \& Sanford 1993a: 27), speakers tend to agree as to how the different QEs relate to each other in size. Nouwen (2010, 236) reports that, when asked to order pairs of QEs in terms of their relative size, speakers generally shared the same intuitions, although some QE pairs showed more variation. In an earlier study where speakers did not compare different QEs, but were simply asked to state what percentage a specific QE corresponded to in a particular context, the 'small' QEs (e.g. very few, few and not many) turned out to be indistinguishable in size (Moxey \& Sanford 1993b). Comparing QEs and deciding what proportions they refer to on their own are thus in part different things.

The size of QEs ${ }^{1}$ is relevant both directly, when interpreting statements using them, and more indirectly, when referring back to QEs using anaphoric expressions (Moxey 2006). Previous research on the size of QEs has focussed on English. As QEs are lexical expressions, they are likely to show differences across languages. Studies targeting other languages are therefore called for, not least so that cross-linguistic comparisons can be made. In this paper, we report the results from a large-scale estimation study investigating the size of seventeen QEs in Swedish.

\section{Background}

The examination of the size of different types of quantifying expressions can have practical implications. Both frequency adverbs (e.g. rarely, sometimes) and modal adjectives (e.g. probable, likely) resemble QEs

1 For simplicity, we will henceforth refer to QEs with large REFERENCE SETS, i.e. with many members in this set, as 'large QEs', and QEs with small REFERENCE SETS as 'small QEs' (see Fig. 1). 
in their vagueness. The former categories often appear in psychometric studies, in which participants are asked to indicate how often a statement applies to them, ticking boxes labelled with these adverbs or adjectives. To interpret the results, it is important to have a fairly precise idea of how participants interpret these expressions (see Moxey \& Sanford 1993a and references therein). There are similar situations where it is important to know how speakers interpret QEs. The size of QEs can also have more indirect relevance, as it can affect the interpretation of anaphoric expressions referring back to QEs.

The meaning of QEs extends beyond the approximate proportion they pick out. For instance, although QEs like few and a few both refer to similarly small proportions, they differ in polarity; few is a NEGATIVE (monotone decreasing) QE, while $a$ few is a POSITIVE (monotone increasing) QE (e.g. Barwise \& Cooper 1981; Peters \& Westerståhl 2006). Positive and negative QEs differ in their entailment patterns. For positive QEs, there is entailment from a subset (yellow socks) to a superset (socks), (2a), while for negative QEs, there is entailment from the superset to the subset, (2b):

(2) a. Most students were wearing yellow socks. entails Most students were wearing socks.

b. Not all students were wearing socks. entails Not all students were wearing yellow socks.

Unlike positive QEs, negative QEs also license NPIs, such as anymore (see e.g. Peters \& Westerståhl 2006):

a. Not all students wear socks anymore.

b. Most students wear socks *anymore.

Both negative and positive QEs pick out the intersection between two sets, stating that some property B holds for members of a set A. In Figure 1 below, Set A is the set of students, and Set B is the set of people listening carefully. The intersection between the two sets is known as the REFERENCE SET (Moxey \& Sanford 1987). When referred back to, positive and negative QEs differ in what set is in focus. For positive QEs, it is still the REFERENCE SET, as illustrated in (4a), while for negative QEs, the focus is often switched to the part of Set A that is not in Set B, known as the COMPLEMENT SET. These would be the students not listening carefully, as illustrated in (4b): 


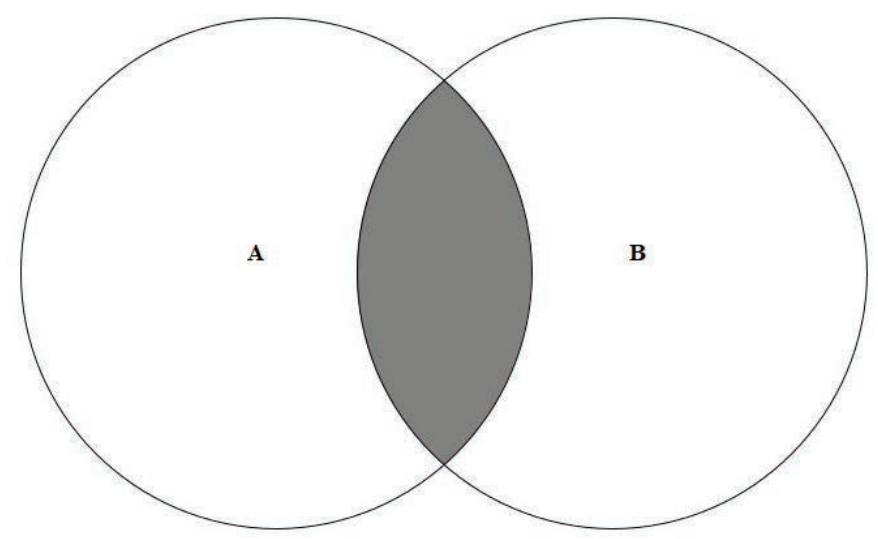

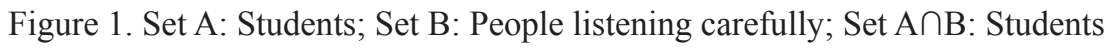
listening carefully, Set A-B: Students not listening carefully

(4) a. A few students listened carefully. They were very interested in the topic.

b. Few students listened carefully. They dozed off right away.

Although the main factor determining which set can be targeted when referring back to a $\mathrm{QE}$ is whether the $\mathrm{QE}$ is positive or negative, it has been suggested that contextual expectations as well as the size of the QE can also play a role for what set is in focus (Moxey 2006, see also Zulaica-Hernández 2018). For example, a positive QE referring to a small proportion (a small number in (5) below) can license a COMPLEMENT SET continuation if the predicate was expected to hold for a much larger proportion (for instance all). In (5), thus, they can refer to the students who didn't come to the party (example from Moxey 2006: 429).

(5) Mrs. Smith expected all the children to finish the essay. A small number of them completed the work. They ran out of ideas and decided to throw the paper around instead.

The size of QEs can be looked at from at least two perspectives: how different QEs compare to each other in size, and what proportions they pick out in context but not in comparison to other QEs. Nouwen (2010) conducted an online survey, where participants were asked to decide 
whether a given relation between QEs held or not. In general, most participants had the same intuition. However, for lots vs many and a couple being equal to exactly two, there was no consensus $(2010,236)$ :

$$
\begin{aligned}
& \text { QE - QE } \\
& \text { oodles }>\text { lots } \\
& \text { lots }>\text { many } \\
& \text { many }>\text { several } \\
& \text { several }>\text { a few } \\
& \text { a few }>\text { a handful } \\
& \text { a handful }>\text { a couple } \\
& \text { a couple = exactly two } \\
& \text { a pair = exactly two }
\end{aligned}
$$

(agree-don't agree)

$(24-2)$

$(34-0)$

In an earlier study, Moxey and Sanford (1993b) looked at different QEs in context, asking participants to decide what percentage they thought the QE corresponded to. Each participant (450 in total) only looked at one single scenario and one single $\mathrm{QE}$, and thus did not compare different QEs to each other. There were three different scenarios, pre-tested to establish that they corresponded to situations where the expected proportions were different. The scenario in (7), below, for example, was found to represent a relatively large proportion $(65.86 \%)$ in the pre-test, whereas the other two scenarios were found to represent a mid-range proportion $(50.01 \%)$ and a small proportion (27.3\%), respectively (1993b: 76$)$ :

(7) The residents' association's annual Xmas party was held last night in the town hall. Question: What percentage of the residents do you think enjoyed the Xmas party?

In the main test, a sentence containing one of the QEs ( $f e w$, a few, very few, only a few, quite a few, not many, many, very many, quite a lot, a lot) was added (1993b: 77):

(8) The residents' association's annual Xmas party was held last night in the town hall.

QUANT of those who attended the party enjoyed what might be called the social event of the year.

Question: What percentage of the residents do you think enjoyed the Xmas party? 
There were two main findings: Firstly, QEs denoting large proportions (i.e. the large QEs quite a lot, many, a lot, very many) showed quite a lot of variation across the scenarios (the low expectancy scenario resulting in significantly lower estimations than the other two), while QEs denoting small proportions (i.e. the small QEs very few, few, not many, a few, quite a few) did not. Secondly, QEs denoting small proportions did not differ significantly in size in relation to each other. In other words, small QEs did not differ in relation to each other and also did not differ across the scenarios, while large QEs differed in both ways.

As QEs are lexical items, the properties of QEs in one language do not necessarily carry over to their translation equivalents in another language. In this paper, we therefore switch the focus to Swedish and investigate what size QEs have in this language.

\section{The size of QEs in Swedish}

In order to find out what size different QEs in Swedish have, we conducted a large-scale estimation study. As in Moxey and Sanford (1993b), the participants considered only one single scenario, with one QE each, and thus did not compare different QEs to each other. Unlike in Moxey and Sanford (1993b), we only had one context, but we specified the total number of members of Set A (see (11) below). The QEs chosen for inclusion in the study were the ones that we intuitively considered to pick out large and small quantities, representing both positive and negative QEs (for the latter categorization, see the Pre-test section below).

\subsection{Material and method}

\subsubsection{Pre-test}

The QEs (see Table 1) used in the main test were also tested in a separate questionnaire to determine whether they are positive (monotone increasing) or negative (monotone decreasing). Eight participants completed the questionnaire in which the tasks were to state whether they thought an entailment relation, as in (9) below, was valid or not, and grade sentences with QEs and NPIs on a scale from 1 (totally unnatural) to 5 (completely natural), as in (10):

(9) a. Om nästan alla tjejer hade skor på sig innebär det att nästan alla tjejer hade gympaskor på sig.

\section{JA NEJ}

(If almost all girls were wearing shoes it means that almost all girls were wearing sneakers.) 
b. Om nästan inga tjejer hade skor på sig innebär det att nästan inga tjejer hade gympaskor på sig.

JA NEJ

(If almost no girls were wearing shoes it means that almost no girls were wearing sneakers.)

(10) a. Nästan alla studenter har lämnat in uppgiften än.

$\begin{array}{lllll}1 & 2 & 3 & 4 & 5\end{array}$

(Almost all students have handed in the assignment yet.)

b. Nästan inga studenter har lämnat in uppgiften än.
1
2
3
4
5
(Almost no students have handed in the assignment yet.)

The results from the pre-test led to the division of QEs that is shown in Table 1.

\subsubsection{Participants}

645 self-reported native speakers of Swedish, all undergraduate students at Lund University or Linnæus University, took part in the estimation study. 47 of them $(7 \%)$ were excluded due to illegible handwriting, being nonnative speakers, or misunderstanding the task. The results presented below are based on the remaining 596 responses.

\subsubsection{Material}

We constructed one experimental item in seventeen different versions, differing only in what $\mathrm{QE}$ was used. Each version consisted of a context sentence stating the total number of set members, followed by a sentence containing one of the seventeen QEs, and finally a question about the number of individuals for which the property holds:

(11) Det var 100 studenter i den stora föreläsningslokalen. QE av dem hade varit där förut. Hur många studenter hade varit där förut? (svara med siffror)

(There were 100 students in the auditory. QE of them had been there before. How many do you think had been there before? (Give your answer in numbers)) 
The QEs that were tested are the ones in Table 1 below. The QE färre än 90 ('fewer than 90') was included in order to investigate whether giving a definite higher limit (a precise number) would affect the range in the answers.

\begin{tabular}{|ll|}
\hline Positive QEs' & Negative QEs \\
\hline det stora flertalet ('the great majority') & få ('few') \\
ett antal ('a number of') & färre än 90 ('fewer than 90') \\
i stort sett alla ('virtually all') & inte alla ('not all') \\
många ('many') & inte exakt alla ('not exactly all') \\
några ('some') & inte många ('not many') \\
några enstaka ('a small number of') & inte precis alla ('not precisely all') \\
några få ('a few') & inte riktigt alla ('not quite all') \\
nästan alla ('almost all') & inte så många ('not so many') \\
& nästan inga ('almost no') \\
\hline
\end{tabular}

Table 1. Positive and negative QEs

\subsubsection{Procedure}

The questionnaire was administered before or after classes. Oral instructions specifying that answers should be given in numbers were provided to make sure that the participants wrote precise numbers rather than relative sizes (such as 'more/less than...'). The participants were under no time pressure to complete the task, but were instructed to write down their immediate intuition.

\subsection{Results}

Figure 2 presents the results from the estimation of the positive QEs. The mean values for each QE is given in the plot. The QEs det stora flertalet ('the the great majority'), $i$ stort sett alla ('virtually all'), nagra ('some') and nästan alla ('almost all') have mean values above 50 and are thus large QEs. The QEs ett antal ('a number of'), några ('some'), några enstaka ('a small number of') and några få ('a few') have mean values below 50 and are thus small QEs.

2 Six of the QEs (många 'many', några 'some', nästan alla 'almost all', få 'few', inte alla 'not all', and inte många 'not many') were tested in a first run, and eleven in a second run. The results from the first run have been reported in Heinat and Klingvall (2019).

3 The English expressions are approximate translations only. 
Starting with the large positive QEs, a statistical analysis shows that they are all significantly different, except $i$ stort sett alla and nästan alla which are statistically indistinguishable. ${ }^{4}$ All the small positive QEs are also significantly different from each other, except for några enstaka and några $f a ̊$, which are statistically indistinguishable.

Estimation of positive quantifiers

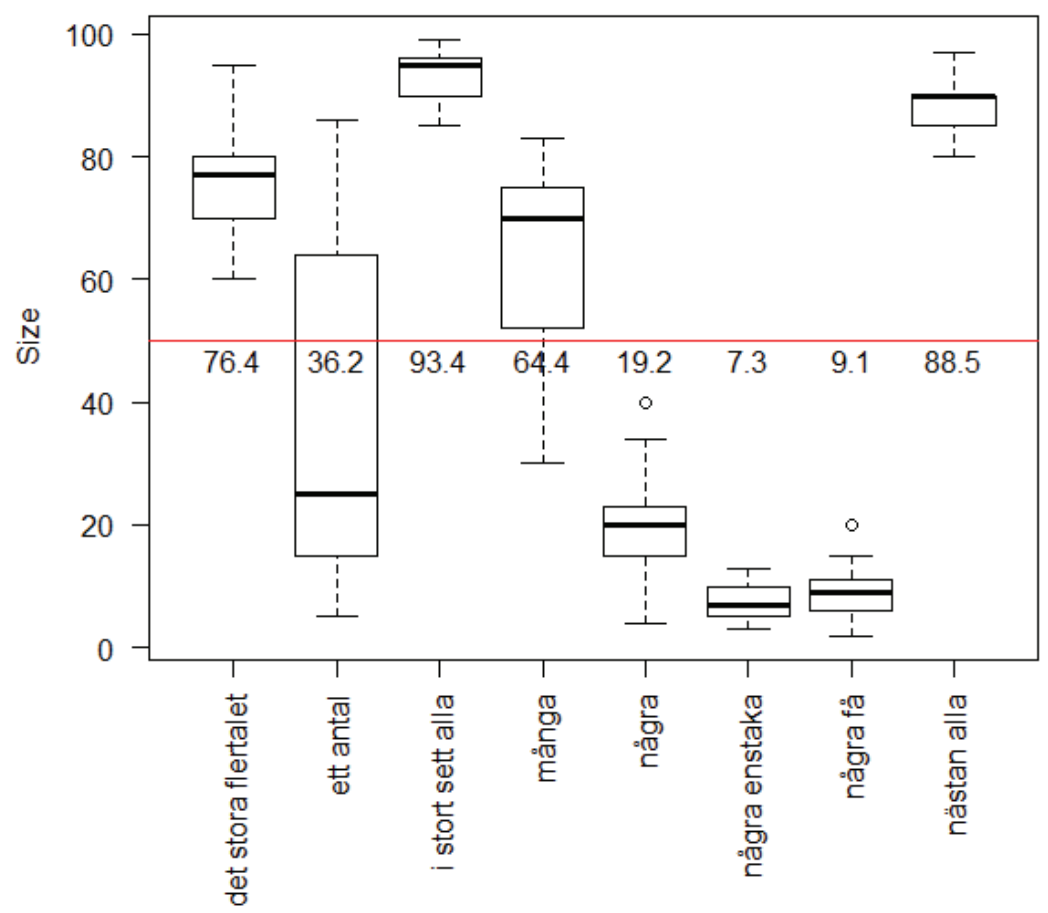

Figure 2. Positive QEs

The QE ett antal ('a number of') stands out among the positive QEs because the estimations vary more than for any of the other ones, ranging from 5 to 86. A closer look (see Figure 3) reveals that this QE has in fact a bimodal distribution. That is, some participants interpret ett antal as picking out some number between 10 and $20 \%$ and while other participants interpret it as referring to some number between 70 and $80 \%$.

4 We fitted a linear model using the $1 \mathrm{~m}$-function in $\mathrm{R}$ (R Core Team 2018) and using the emmeans-package for pairwise comparison of the QEs (Lenth 2018). The $p$ values reported as significant here are $<0.05$. 


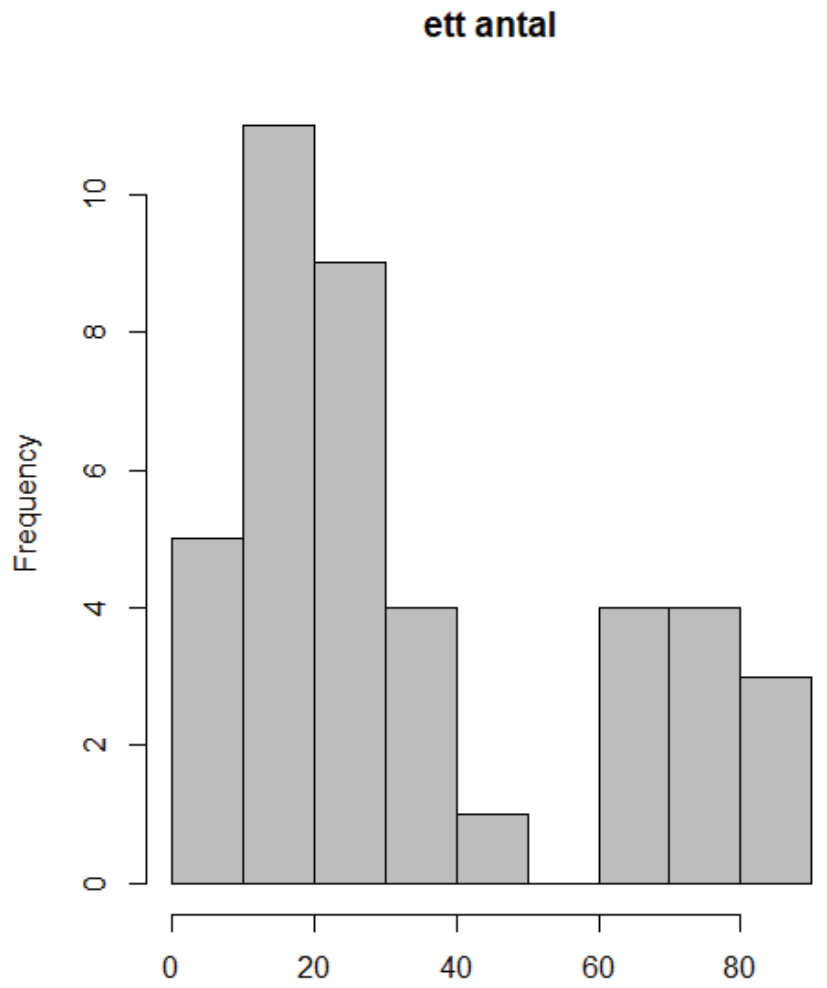

Figure 3. Distribution for ett antal ('a number of')

Figure 4 presents the results from the estimation of the negative QEs. The mean values for each QE is given in the plot. The QEs färre än 90 ('fewer than 90'), inte alla ('not all'), inte exakt alla ('not exactly all'), inte precis alla ('not precisely all') and inte riktigt alla ('not quite all') have mean values above 50 and are thus large QEs. The QEs $f a ̊$ ('few'), inte många ('not many'), inte så många ('not so many') and nästan inga ('almost no') have mean values below 50 and are thus small QEs.

As for the large negative QEs, the results are rather complex. A statistical analysis shows that the QE färre än 90 is indistinguishable from inte alla, but different from all other large negative QEs. The QEs inte exakt alla, inte precis alla and inte riktigt alla are also indistinguishable from each other. The QE inte alla is also indistinguishable from inte precis 
alla and inte riktigt alla, but it is significantly different from inte exakt alla. In other words, the large negative QEs form three partly overlapping groups: A. färre än 90 and not all; B. inte alla, inte precis alla and inte riktigt alla; $\mathrm{C}$. inte exakt alla, inte precis alla and inte riktigt alla. All the small negative QEs are statistically indistinguishable except for inte så många and nästan inga, which are significantly different from each other.

\section{Estimation of negative quantifiers}

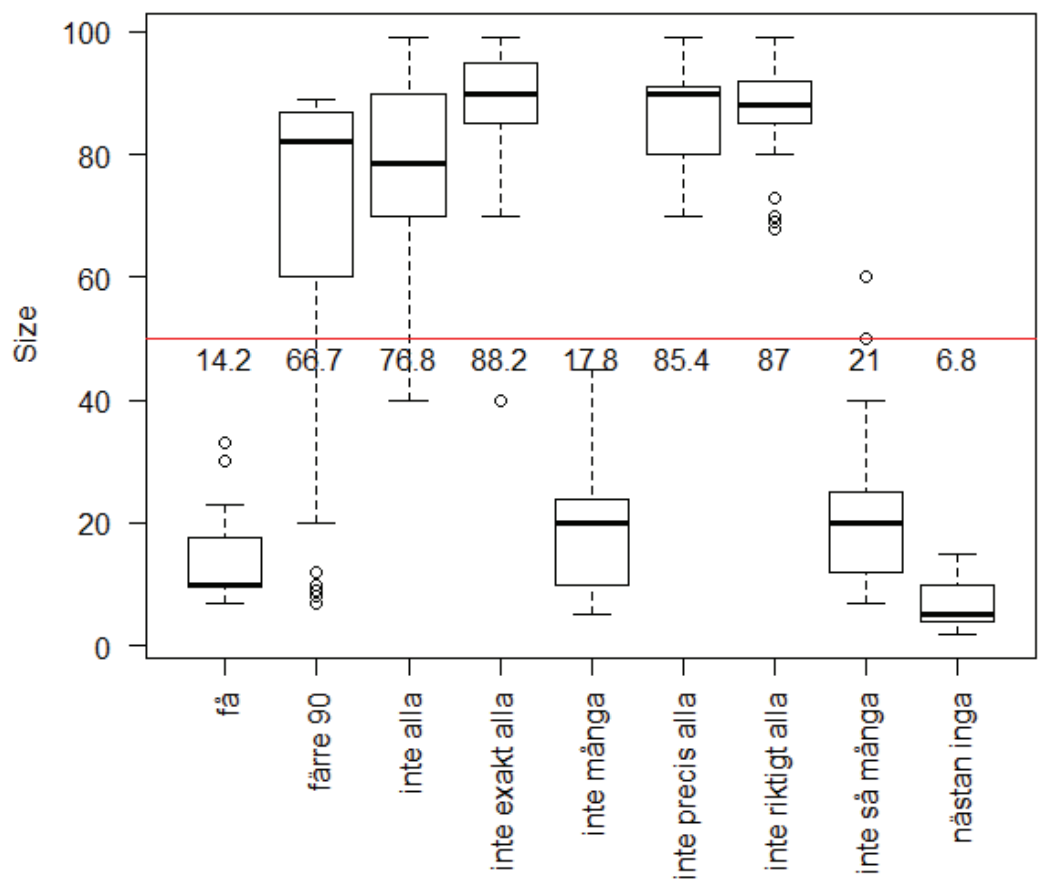

Figure 4. Negative QEs

As mentioned in section 3.1.3, the QE färre än 90 ('fewer than 90) was tested in order to see whether specifying an upper limit, in this case 90, would affect the ratings. As seen in Figure 5, the ratings range from very small values (7) to almost 90 (89). However, the great majority (24 of 38, $63 \%$ ) rates the $\mathrm{QE}$ as 80 or higher. 


\section{färre 90}

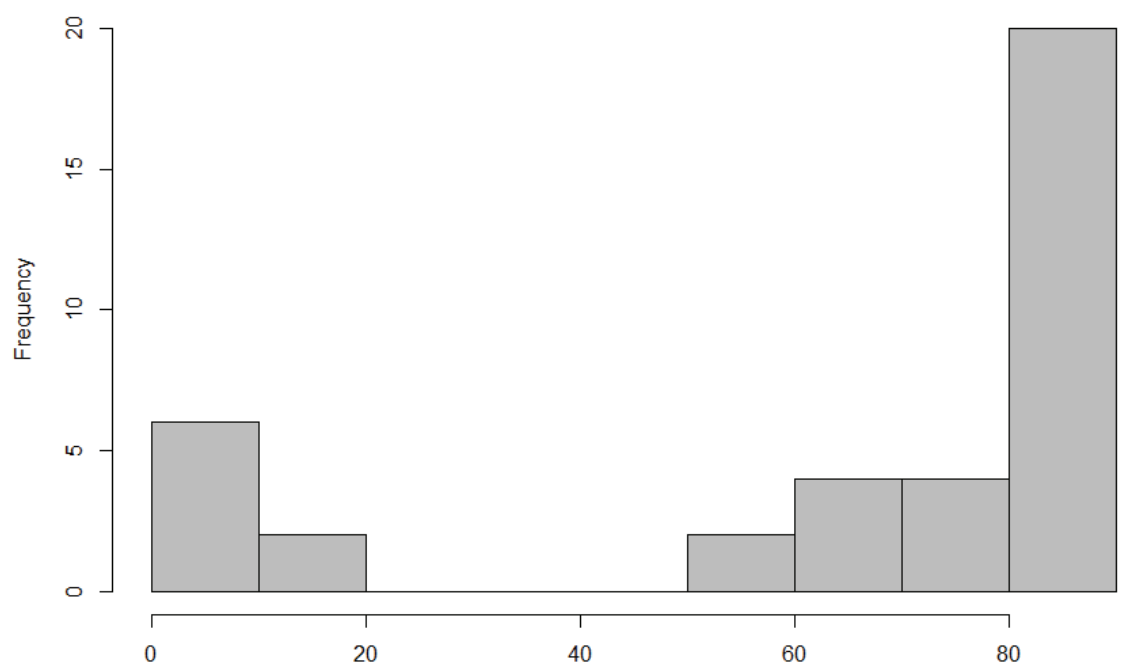

Figure 5. Distribution for färre än 90 ('fewer than 90')

\section{Discussion}

The results from this study are in part similar to those found for English by Moxey and Sanford (1993b). In their study, the small QEs were indistinguishable in size while the large ones were significantly different in size. This is more or less what we find for small negative QEs and large positive QEs, but not for large negative and small positive ones. It should be noted, though, that the large QEs used by Moxey and Sanford (1993b) were positive and the small ones were negative (with the one exception of $a$ few. ${ }^{5}$ Thus it seems that positive QEs pick out more clearly defined quantities than do negative QEs. Obviously, this can depend on the individual QEs we have tested, but we think that we have actually looked at the great majority of large and small QEs, both positive and negative. It is therefore possible that the distinction is really tied to polarity. At this point it is unclear why this should be the case, but it might be related to the

5 Moxey and Sanford (1993b) also included the positive QE only a few. The focusing element only made the behaviour of this QE very odd, and we do not think it is comparable to the small QEs used in the present study. The reader is referred to Moxey and Sanford (1993b) for details 
fact that positive polarity is the default. In an out of the blue question, the positive QE many would be used, as in How many times have you been to Paris?, rather than the negative few, as in How few times have you been to Paris?

The fact that some of the QEs are indistinguishable in the estimation study made us conduct a small follow-up investigation. Twelve participants rated pairs of QEs in terms of their relative size, i.e. whether one of the members of the pair is larger, smaller or equal to the other member, as in (12):

(12) A: inte alla - B: inte exakt alla

$\mathrm{A}$ is larger than $\mathrm{B}$

$\mathrm{B}$ is larger than $\mathrm{A}$

$\mathrm{A}$ and $\mathrm{B}$ are equal in size

Some of the QEs that were indistinguishable in the estimation task were rated as follows, in the follow-up investigation: ${ }^{6}$

\begin{tabular}{|l|l|l|l|l|}
\hline A & B & A $>$ B & A = B & A $<$ B \\
\hline i stort sett alla & nästan alla & 7 & 4 & 1 \\
\hline några enstaka & några få & 0 & 8 & 4 \\
\hline inte alla & inte precis alla & 1 & 3 & 8 \\
\hline inte exakt alla & inte precis alla & 6 & 5 & 1 \\
\hline inte precis alla & inte riktigt alla & 4 & 6 & 2 \\
\hline få & inte många & 3 & 7 & 2 \\
\hline inte många & inte så många & 0 & 8 & 4 \\
\hline
\end{tabular}

Table 2. Relative size of some QEs

As seen in Table 2, the ratings vary quite a lot and there is no pair that everyone agrees on. Also in this follow-up investigation, some of the pairs are judged as representing QEs of the same size by a majority of the participants (några enstaka - några få, få - inte många and inte många inte så många). In light of Moxey and Sandford's discussion (1993a) about

6 The follow-up investigation included a sub-selection of the QEs that had the same rating in the estimation task. 
the informativeness of using QEs instead of absolute numbers (see Section 1), it is unclear to us exactly what different information these QEs convey, but it is a question for future research.

One result worth highlighting is the bimodal distribution of the QE ett antal ('a number of'). As we saw, some participants ascribe a small number to this QE, whereas others ascribe it a high number. The estimation study gives us no clues as to the reason for the result. As shown by Moxey and Sanford (1993b), the context is very important for the interpretation of QEs. Expectations and real-world knowledge influence the size of the REFERENCE SET of a QE; many female doctors would pick out a smaller number than many male doctors and many ants would pick out more individuals than many elephants. In the present study we tried to make sure that the test sentence does not induce any strong expectations tied to individual participants.

As we see it, there are two possibilities for the bimodal distribution of ett antal. Either the QE ett antal is unambiguous for speakers of Swedish, and people fall into one of two categories; one category that ascribes ett antal a small number, and one category that ascribes it a large number. Or this QE is ambiguous and can pick out a small and a large number for all speakers of Swedish. Our findings seem to support the first possibility, i.e. that ett antal is not ambiguous for individual speakers. In the task, participants can only choose one interpretation, irrespective of whether the $\mathrm{QE}$ is ambiguous to them or not. If this QE was ambiguous for speakers in general, the number of people rating it as large should be more or less equal to the number of people rating it as small, since, all things being equal, there is a chance of fifty percent of choosing one over the other. Given the participants' preference for rating it as a small QE, we therefore favour the first assumption (that speakers fall into one of two categories). If this is the case, it raises interesting questions about how this QE is used. The following is a quote from an Op-Ed in Sydsvenska dagbladet (Feb. 24, 2019) about the possibilities of extracting vanadium in Österlen in Skåne:

(13) Men om det förekommer finns det i vanlig jord och kan därför tas fram betydligt enklare och med små ingrepp på ytor som motsvarar ett antal fotbollsplaner.

("But if it is there, it is in ordinary soil and can therefore be extracted much easier and with minor operations on areas corresponding to a number of football fields.") 
Whether "a number of football fields" is around two, three or around twenty, twenty-five is arguably crucial for an informed decision on this matter.

Including a specific number as an upper limit, as in the QE färre än 90 ('fewer than 90'), made most participants give ratings quite near the upper limit. In our view, this is the expected behaviour and it is in line with a so-called pragmatic interpretation of this QE. In the literature there is distinction between logic and pragmatic interpretations of QEs (Horn 1972). The latter interpretation is known as a SCALAR IMPLICATURE. In our scenario, the pragmatic interpretation is that if the information was available that there were as few as 20 students present (which is compatible with 'fewer than 90'), then providing the information that there were 'fewer than 90' present would flout the Gricean maxim of quantity (Horn 1972). That is, if 90 is specified, there is reason to believe that the number is very close to 90 .

In the literature, the QEs that have received most attention regarding scalar implicature are some and not all (see e.g. Sperber \& Wilson 1986; Chierchia 2004; Horn 2006; Nieuwland et al. 2010; Spychalska et al. 2016). The logic interpretation of the QE some, for example, is "at least some", while the pragmatic interpretation is "at most some". On its logic reading, the sentence some students were at the lecture is thus compatible with the interpretation "some, in fact all, students were at the lecture" while on the pragmatic reading it is rather "some, but crucially not all, students were at the lecture". This pragmatic interpretation of some involves a narrowing, and even negation, of the stronger expressions all (Nieuwland et al. 2010: 325). Investigating scalar implicature was not part of the aim of the present estimation study, but since both the corresponding Swedish expressions några ('some') and inte alla ('not all') are included in the study we will briefly discuss them. Not only are några and its corresponding scalar implicature inte alla of different polarity, but they also pick out very different numbers, as seen in Figures 6 and 7. 


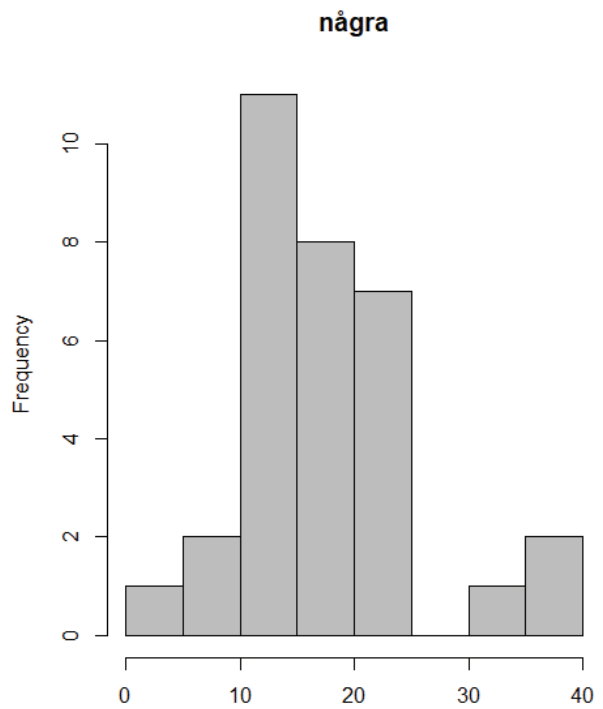

Figure 6. Distribution for några ('some')

inte alla

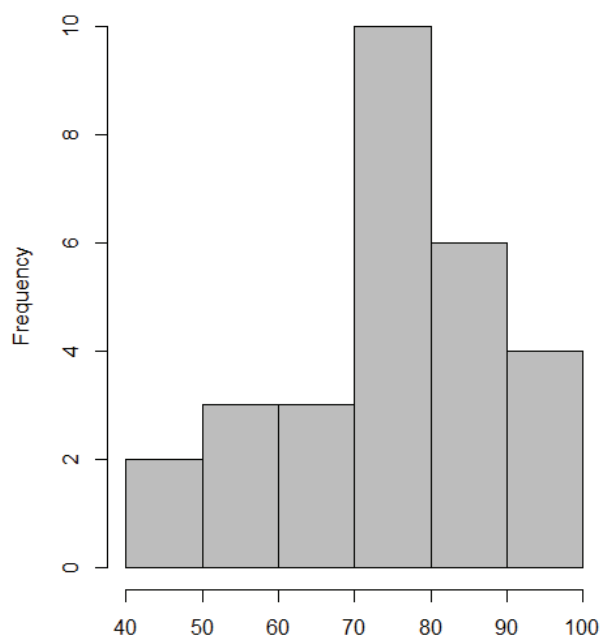

Figure 7. Distribution for inte alla ('not all') 
The QE några is small and the QE inte alla is large. Thus, the two QEs have mean values below and above 50, respectively, although there is a small overlap between the two with 2 participants giving nagra and 1 participant giving inte alla an estimate of 40. From these results we draw the conclusion that in Swedish, the pragmatically inferred inte alla does not correspond to några in a numeral sense. In fact, in a previous study we show that nagra, which is a positive QE, shows no signs of being treated as a negative QE, which inte alla is (Heinat \& Klingvall 2019). The fact that the two QEs show such different qualities in both size and polarity obviously raises important questions about what kind of interpretation scalar implicatures is. It is obviously not just a matter of turning one QE, några, into another QE, inte alla, as claimed by Nieuwland et al. (2010). Instead the interpretation of några as inte alla must take place at another level of interpretation than where QEs get their interpretations. This semanticpragmatic relation between quantificational and inferred quantificational interpretations is something that needs further investigation and cannot be resolved based on the present study.

A final note on the internal structure of QEs. We find that the interaction between quantifiers raises interesting issues for their compositional semantics. In our pretest targeting the monotonic properties of the QEs, we found that for all QEs consisting of an overt negation plus a QE, such as inte många ('not many'), and one QE combined with another QE, några $f a$, the full expression always gets the polarity of the first operator. While många is a positive $\mathrm{QE}$, inte mainga is negative because inte is a negative operator, and, conversely, although $f a ̊$ is negative, några $f a ̊$ is positive because några is a positive operator. As is well-known, in sentences with more than one QE, it is possible to get reverse scope. Sometimes this is even the only sensible interpretation, as in the following sentence:

(14) Servitören la en sked på alla borden.

'The waiter put a spoon on all the tables'

In this example, an interpretation where the universal quantifier (alla 'all') takes scope over the existential quantifier (en 'a') is the only sensible one: every table is such that the waiter put a spoon on it. The interpretation with surface scope is nonsensical: there is a spoon such that the waiter put it on every table. Looking at the interaction of QEs in the complex 
QEs described above, we never find reverse scope relations. Instead, the first QE always determines the polarity of the whole QE. For some reason, which we will not try to find out here, we thus cannot get reverse scope inside complex QEs, for example letting the negation in $f a$ scope out of the QE några få.

\section{Conclusion}

In a large-scale estimation study, we investigated the size of the REFERENCE SET for seventeen different QEs in Swedish. The estimations from 596 participants showed that, in general, positive QEs pick out more clearly defined quantities than negative QEs. One particular QE, ett antal ('a number of'), turned out to have a bimodal distribution, being rated as either large or small. In a small follow-up study, some of the indistinguishable QEs could be ordered in size relative to each other, but most of them could not and were rated as of the same size.

It is not clear why we got the distinction between positive and negative QEs regarding significant differences in size, and this requires further research. Regarding the bimodal distribution of the QE ett antal, we hypothesized that speakers fall into one of two categories. Either they ascribe the QE a small size, which a majority of the participants did, or they ascribe the QE a large size. Based on the differences between the number of participants giving it a large or a small rating, we find it less likely that the QE itself is ambiguous.

Regarding the QE några and its corresponding scalar implicature inte alla, we found that they pick out very different sizes and that the interpretations of scalar implicature is most likely different from the interpretation of QEs.

We also noted that even though QEs can give rise to reversed scope readings at the clausal level, there is no indication that this is possible inside complex QEs such as några få and inte alla. The first operator always determines the polarity of the complex QE.

This investigation, though strictly empirical and descriptive, gives rise to many questions, theoretical and psycholinguistic, all of which require further research. 


\section{References}

Barwise, Jon \& Robin Cooper. 1981. Generalized quantifiers and natural language. Linguistics and Philosophy 4(2). 159-219.

Chierchia, Gennaro. 2004. Scalar implicatures, polarity phenomena, and the syntax/pragmatics interface. In Adriana Belletti (ed.) The Cartography of Syntactic Structures. vol. 3, Structures and Beyond, 39-103. New York: Oxford University Press.

Heinat, Fredrik \& Eva Klingvall. 2019. Anaphoric reference to quantified expressions in Swedish. Journal of Psycholinguistic Research 48(3): 551-568. doi:10.1007/s10936-018-9618-z.

Horn, Laurence Robert. 1972. On the semantic properties of logical operators in English. Los Angeles, CA: University of California dissertation.

Horn, Laurence Robert. 2006. The border wars: A neo-Gricean perspective. In Klaus von Heusinger \& Ken Turner (eds.) Where semantics meets pragmatics. 21-48. Amsterdam: Elsevier.

Keenan, Edward L. \& Jonathan Stavi. 1986. A semantic characterization of natural language determiners. Linguistics and Philosophy 9. 253-326.

Lenth, Russell. 2018. emmeans: Estimated marginal means, aka least-squares means. URL https://CRAN.R-project.org/package $=$ emmeans, $r$ package version 1.3.1.

Moxey, Linda M. 2006. Effects of what is expected on the focussing properties of quantifiers: A test of the presupposition-denial account. Journal of Memory and Language 55. 422-439. doi:10.1016/j.jml.2006.05.006

Moxey, Linda M., \& Anthony J. Sanford. 1987. Quantifiers and focus. Journal of Semantics 5. 189-206. doi:10.1093/jos/5.3.189

Moxey, Linda M. \& Anthony J. Sanford. 1993a. Communicating quantities. Exeter: Lawrence Erlbaum.

Moxey, Linda M. \& Anthony J Sanford. 1993b. Prior expectation and the interpretation of natural language quantifiers. European Journal of Cognitive Psychology 5. 73-91. doi:10.1080/09541449308406515

Nieuwland, Mante S., Tali Ditman \& Gina R. Kuperberg. 2010. On the incrementality of pragmatic processing: An ERP investigation of informativeness and pragmatic abilities. Journal of Memory and Language 63. 324-346. doi:10.1016/j.jml.2010.06.005

Nouwen, Rick. 2010. What's in a quantifier? In Martin Everaert, Tom Lentz, Hannah de Mulder, Øystein Nilsen \& Arjen Zondervan (eds.) The linguistics enterprise: from knowledge of language to knowledge in linguistics. 235-256. Amsterdam: John Benjamins.

Peters, Stanley \& Dag Westerståhl. 2006. Quantifiers in language and logic. Oxford: Oxford University Press.

R Core Team. 2018. R: A language and environment for statistical computing. R Foundation for Statistical Computing, Vienna, Austria. 
Sperber, Dan \& Deirdre Wilson. 1986. Relevance: communication and cognition. Oxford: Blackwell.

Spychalska, Maria, Jarmo Kontinen \& Markus Werning. 2016. Investigating scalar implicatures in a truth-value judgement task: evidence from event-related brain potentials. Language, Cognition and Neuroscience 31. 817-840. doi:10.1080/2 3273798.2016.1161806

Westerståhl, Dag. 1985. Determiners and context sets. In Alice ter Meulen \& Johan van Benthem (eds.) Generalized quantifiers in natural language. 45-71. Dordrecht: Foris.

Zulaica-Hernández, Iker. 2018. Complement anaphora in Spanish: Reference and discourse relations. Journal of Psycholinguistic Research 43. 449-466. doi:10.1007/s10936-017-9527-6 